\title{
Synaptic activity and (neuro)inflammation in Alzheimer's disease: could exosomes be an additional link?
}

Hermine Counil $^{1 *}$, Slavica Krantic ${ }^{1 \#}$

${ }^{I}$ Inserm UMRS 938, St. Antoine Res Ctr, Paris, France;

"Present address : INRS- Institut Armand Frappier, Laval, Canada, QC

${ }^{\#}$ Corresponding author: Dr Slavica KRANTIC

\author{
INSERM UMRS 938 \\ Team "Immune System and Neuroinflammation" \\ Hôpital Saint-Antoine \\ 184 rue du Faubourg St-Antoine \\ 75012 Paris, FRANCE \\ Tel: +33149286695 \\ slavica.krantic@inserm.fr / slavica.krantic@gmail.com
}

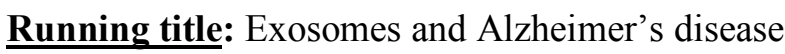




\begin{abstract}
Nanosized extracellular vesicles, known as exosomes, are produced by all cell types in mammalian organisms and have been recently involved in neurodegeneration. In the brain, both glia and neurons give rise to exosomes, which contribute to their intercellular communication. In addition, brain-derived exosomes have a remarkable property to cross blood-brain-barrier bi-directionally. In this line, exosomes of central origin have been identified in peripheral circulation and already considered as putative blood biomarkers of neurodegenerative diseases, including Alzheimer's disease (AD). Moreover, tentative use of exosomes as vehicle for the clearance of brain-born toxic proteins or, conversely, neuroprotective drug delivery, was also envisaged. However, little is known about the precise role of exosomes in the control and regulation of neuronal functions. Based on the presence of subunits of glutamate receptors in neuron-derived exosomes on one hand, and complement proteins in astrocyte-derived exosomes on the other hand, we hypothesize that exosomes may participate in the control of neuronal excitability via inflammatory-like mechanisms both at the central level and from the periphery. In this review, we will focus on AD and discuss the mechanisms by which exosomes of neuronal, glial and/or peripheral origin could impact on neuronal excitability either directly or indirectly.
\end{abstract}

$\underline{\text { Key words: }}$ exosomes, Alzheimer's disease, synaptic activity, neuronal excitability, glial cells. 


\section{THE COMPLEXITY OF ALZHEIMER'S DISEASE}

Alzheimer's disease (AD), an age-related neurodegenerative disease, is a major public health problem in developed countries with important social and economic outcomes. Cognitive impairments, including memory loss and mood disorders, are the main clinical symptoms. Patients suffer further from language and psychiatric dysfunctions as well as subtle alterations of executive functions that inexorably progress leading to a complete loss of autonomy and dementia at advanced stages. $\mathrm{AD}$ is marked by a long pre-clinical asymptomatic stage ranging from 10 to 20 years, depending on the etiology (familial or sporadic) (see [1] and references cited therein).

\section{Main hallmarks of pathogenesis}

Genetic studies have identified mutations in the amyloid- $\beta(\mathrm{A} \beta)$ precursor protein $(\mathrm{A} \beta \mathrm{PP})$, presenilin-1 and -2 (PS1, PS2) genes that cause the rare familial forms of AD (FAD). The proteolysis of $\mathrm{A} \beta \mathrm{PP}$ by $\mathrm{BACE}$ ( $\beta$-site $\mathrm{A} \beta \mathrm{PP}$ cleaving enzyme) yields $\beta \mathrm{CTF}$ ( $\beta$-secretase generated C-terminal fragment) which is followed by the PS-containing gamma-secretase complex cleavage of $\beta \mathrm{CTF}$ yielding $\mathrm{A} \beta$ peptides of different sizes (i.e. composed of 38 to 42 amino acids: $A \beta_{1-38}$ to $A \beta_{1-42}$ ). The accumulation of monomeric and oligomeric forms, as well as conformational misfolding changes, leads to extracellular deposition of $\mathrm{A} \beta$ peptides in insoluble amyloid plaques (A $\beta$-plaques). The amyloid hypothesis [1] posits that $\mathrm{A} \beta$ peptides play a pivotal role in $\mathrm{AD}$ pathogenesis by triggering the pathological "amyloid cascade" which consists in early synaptic dysfunction, microglial and astrocyte activation and hyperphosphorylation of Tau proteins. The intracellular accumulation of abnormally hyperphosphorylated Tau (pTau) triggers neurofibrillary tangles (NFTs) formation, and further contributes to synaptic and neuronal dysfunctions leading to neuronal loss and macroscopic atrophy, which culminates in extensive neurodegeneration. This hypothesis further posits that 
synaptic dysfunction precedes alterations in neurotransmitter release, and thus impairment of memory and cognitive functions [1].

The reasons for the latency between $\mathrm{A} \beta$ deposition (amyloidosis) and clinical symptom onset are currently unknown [2]. Importantly, alterations of neuronal activity appear already during early stages of AD. For example, the risk of epileptic seizure is increased in sporadic $\mathrm{AD}$ and more than $40 \%$ of $\mathrm{AD}$ patients display subclinical epileptiform activity according to a recent clinical study [3]. This increased risk has been also reported in AD-like mouse models of amyloidosis during the pre-symptomatic stage (i.e. prior to $A \beta$-plaque deposition and cognitive impairment, reminiscent of the pre-clinical stage in humans). These seizureassociated phenomena might be due to the alteration of neuronal membrane properties by soluble $A \beta$, resulting in hyperexcitability of hippocampal pyramidal cells and subsequent epileptiform activity [4]. The latter may be further related to inhibition of long-term potentiation (LTP) [5], a form of synaptic plasticity required for learning and memory. Besides, the impact of Tau protein on synaptic activity has been studied much less than the impact of $A \beta$. Nevertheless, the recent evidence strongly suggests that soluble forms of Tau alter neuronal (including synaptic) functions during the early stages of AD (reviewed [6]). Other mechanisms can also contribute to early neuronal dysfunction including, for instance, high release of reactive oxygen species (ROS) known for their impact on neuronal excitability and synaptic activity [7].

\section{Diagnosis and factors of pathogenesis: focus on neuroinflammation}

$\mathrm{AD}$ can be currently diagnosed earlier than in the past due to a specific phenotype as determined by neurocognitive testing combined with analysis of biomarkers [8]. However, diagnosis is still made at the stage when neuronal lesions are already advanced, making the development of curative treatments highly challenging. In spite of the relatively late diagnosis, considerable progress has been made recently so that modification of biomarkers can be now 
detected at the stage of mild cognitive impairment (MCI), corresponding to the prodromal stage of $\mathrm{AD}$, though before major cognitive and executive function disability occur [8].

In addition to age, which is a major risk factor for developing $\mathrm{AD}$, it is generally recognized that a complex interplay between genetic and environmental factors impact AD pathogenesis [9]. Among genetic factors, the expression of $\varepsilon 4$ allele of apolipoprotein E (APOE4), which plays a crucial role in regulating cholesterol metabolism, severely increases the risk of AD. Other significant genetic risk factors for $\mathrm{AD}$ are mutations in the Triggering Receptor Expressed on Myeloid cells 2 (TREM2), Complement Receptor-1 (CR1), CD33, among others, which are associated with microglia dystrophy, decreased phagocytosis, and an increased proinflammatory phenotype [9]. Most importantly, more than 2/3 of identified risk SNP (Single Nucleotide Polymorphism) mutations reported by genome-wide association studies (GWAS) are exclusively or mostly expressed by microglia. This strongly suggests that microglia, the major mediator of innate immunity in the brain, play a key role in AD pathogenesis which has been previously underestimated [10]. Overall, the majority of identified risk factors are related to inflammatory-, cholesterol metabolism-, and endosomal-vesicle recycling pathways.

In agreement, $\mathrm{AD}$ has been associated with chronic innate inflammation in the central nervous system (CNS). Such neuroinflammation involves activated microglia and reactive astrocytes, increased production of cytokines, chemokines and other inflammatory factors, as well as infiltration of immune cells followed by secondary neurodegeneration [11]. Interestingly, peripheral T-cells in old subjects and $\mathrm{AD}$ patients display higher A $\beta$-reactivity than those coming from neurologically normal subjects [12]. Enhanced T-cell infiltration was observed in the brain of APPPS1 mouse model, while peripheral modulation of T-cell subsets was reported to impact on local CNS innate neuroinflammatory responses [13]. Systemic inflammatory factors have also been suggested to modulate AD-related neuroinflammation [14], as well as peripheral innate immune cells such as neutrophils [15]. Altogether these data 
point to a key role of CNS innate neuroinflammatory responses in the pathophysiology of $\mathrm{AD}$, as well as the complex interplay between local (innate) and peripheral (both innate and adaptive) immunity.

Importantly, recent clinical studies suggested that neuroinflammatory-like changes (i.e. glial activation, release of pro-inflammatory factors and neuronal damages) occur very early (i.e. from pre-clinical stages) in the course of $\mathrm{AD}$ progression [16]. These changes are associated with microglia activation and appear beneficial [17], but microglia progressively switches from homeostatic to disease-associated microglia (DAM) phenotype [18]. Such ADrelated functional switch alters not only the phagocytic function of these cells and their ability to restrict cerebral $A \beta$ accumulation, but also their steady-state surveying and regulatory functions including cytokine, chemokine and growth factor production [18]. Consistently, reduction of chronic neuroinflammation by decreasing the pro-inflammatory cytokine levels in APPPS1 mice improves cognitive performance both at the onset and in advanced stages of ADlike pathology [19]. Moreover, the synaptic hyperexcitability observed in early stages of AD pathogenesis [4] is related to the neuroinflammatory-like changes, such as TNF $\alpha$ induction [20]. Most importantly, by using XPro1595 antagonist to block TNF $\alpha$ actions during the presymptomatic stages of $\mathrm{AD}$, neuronal hyperexcitability, LTP and cognitive impairments were prevented at the later, advanced stages in TgCRND8 mice [21]. These data demonstrate the causal relationship between early pro-inflammatory cytokine production and cognitive dysfunctions.

\section{Pathogenic spread of $A D$}

A growing body of evidence suggests that $\mathrm{AD}$, besides other neurodegenerative disorders, propagates in the brain via prion-like intercellular induction of protein misfolding. Neurotoxic proteins $A \beta$ and pTau share properties with classical prions, including their ability to spread within the brain and the periphery [22]. This capacity is of fundamental importance since it 
corroborates the possibility that sporadic $\mathrm{AD}$ could be triggered in vulnerable brain regions by $\mathrm{A} \beta / \mathrm{pTau}$ seed that may be imported, and not only by in situ production of these proteins. In the next two sections we will focus on $A \beta$ since the prion-like mode of pTau spread, although convincingly demonstrated (for recent review, see [23]), is likely secondary to A $\beta$ propagation because $A \beta$ changes are detectable before those of Tau, at least in FAD ([24,25]; see also discussion in [1]).

Direct neuron-to-neuron transfer of soluble oligomeric $A \beta$ has been also observed in primary cultures of hippocampal rat neurons [26]. Moreover, in vivo transfer of A $\beta$ aggregates by passive, extracellular diffusion from neurons has been suggested (reviewed in [27]), pointing to their putative propagation along interconnected regions in the brain.

In addition to such neuron-mediated propagation, activated microglia and astrocytes may also be involved. Both types of glia cells are usually present near A $\beta$ plaques and NFTs in the hippocampus of $\mathrm{AD}$ patients. The impaired clearance of $\mathrm{A} \beta$ deposits by glial cells contributes to their cerebral accumulation and subsequent spread in the brain, in line with the reported lowered clearance abilities of $\mathrm{AD}$-associated microglia [28]. In addition, increase in $\mathrm{A} \beta$ is concomitant with microglia activation which is in turn accompanied with increased production of pro-inflammatory cytokines (TNF $\alpha$, IL-1 $\beta$, IL-6, IL-12...) [14,28]. These brain-born cytokines may act synergistically with peripheral cytokines [28] to further impair the integrity of the blood-brain barrier (BBB) and thus implement a feed-forward vicious cycle of amplification in terms of production and propagation of cytotoxic proteins [16].

\section{EXOSOMES: NEW PLAYERS IN CELL-TO-CELL COMMUNICATION}

From the data discussed in the previous section, it appears that, by analogy to cancer and autoimmune diseases, AD may be now considered as a pathology of cell-communication. The AD-related impairment of cell communication is likely triggered by the accumulation of toxic 
proteins and involves not only synaptic dysfunction as initially proposed by "amyloid cascade hypothesis" more than 25 years ago [1], but also the altered communication between glia cells and neurons, as well as impaired inter-glia cell communication. In this light, it is interesting to consider the possible involvement of exosomes, now recognized as important mediators in cellular communication and in the pathogenesis of $\mathrm{AD}$.

\section{Definition and general considerations}

Extracellular vesicles (EVs) are nano-sized structures released by all mammalian cell types and found in different body fluids, including CSF and blood [29]. EVs are surrounded by a lipid bilayer and comprise vesicles ranging from 30 to over $1,000 \mathrm{~nm}$ in size. They carry a complex cargo composed of specific proteins such as signaling molecules (integrins, cytokines...) and their receptors, bioactive lipids, nucleic acids including RNAs (mRNAs, miRNAs, small non coding RNAs) and DNAs [29]. Nature of molecular species and their relative proportion in the cargo are highly diversified among EVs, likely reflecting heterogeneity of their cellular origin and microenvironment in which they are generated. The precise characteristics, as well as regulatory mechanisms of biogenesis, sorting and degradation or secretion of EVs are not completely understood so far.

EVs can be divided in two major families: i) microvesicles released by budding of the cellular membrane and ii) exosomes secreted via exocytosis from multivesicular bodies (MVBs) that are formed along the endocytic pathway [29]. Currently, it remains difficult to discriminate between EVs and exosomes and there is no consensus about the specific markers allowing to distinguish between EV subtypes. The International Society for Extracellular Vesicles (ISEV) thus recommends to denote exosomes as "small EVs" based on their size (30$100 \mathrm{~nm}$ ) [30]. For the purpose of this review, the terms "exosomes" and "EVs" are used as per publication to which each particular citation refers to. It should be however kept in mind that in majority of publications using term "exosome", this denomination is based mainly on the 
size criterion without demonstrating the presence of endosomal markers to confirm their endocytic origin.

All EVs contain different proteins involved in their transport and fusion during biogenesis [29]. These proteins can be common to all EVs, comprising transmembrane proteins, tetraspanins, heat shock proteins, lipid-related proteins, and phospholipases. Alternatively, cargo proteins can be specific for a given class of exosomes depending on a donor cell in which they are generated [29]. For example, miRNA-141 is specific for the cargo of exosomes derived from metastatic cells [31].

EVs are also characterized by specific surface marker proteins, such as CD9 and CD81 [32] (Table 1). Exosomes, as a particular class of EVs and in relation to their endosomal origin, express the common markers as for instance CD81, ALIX (ALG-2 interacting protein), Tsg 101 (Tumor susceptibility gene 101) and tetraspanins [29] (Table 1). The content of the cargo and the macromolecule composition differ depending on the physiological state of the donor cell, and can be altered in diseases [29].

Biogenesis, sorting and degradation of exosomes has been extensively discussed in excellent recent reviews (e.g. $[29,33])$ and will not be detailed here. The exosome's life cycle can terminate by degradation of their components that may be used by the recipient cells for the biogenesis of their own constituents or in their intermediate metabolism [29]. Even though, molecules contained in exosomes can also escape degradation and act as bioactive factors to regulate the cell target functions, including in different cell types in the nervous system [34].

\section{Physiological roles of exosomes in the brain}

Classically, the exosome secretion is seen as an excretion of unnecessary or toxic molecules by donor cells [35]. However, as already discussed above, growing body of evidence suggests that exosomes play also a role in intercellular communication involving neighboring and distant cells in the same or different organs [29,36] (Figure 1). 
In the brain, exosomes are produced by oligodendrocytes, neurons, astrocytes, microglia and Schwann cells, as well as by endothelial cells of the brain blood vessels [37]. Their role in reciprocal communication between neurons and glial cells, synaptic plasticity and neuronal activity has recently attracted much interest. For instance, delivery of exosomes carrying myelin-associated proteins derived from oligodendrocytes to neurons establishes communication between these cells, contributing to myelination and maintenance of neuronal integrity [38]. Additional physiological roles of exosomes in the control of neuron-glia interactions include microglia-mediated regulation of synaptic pruning [38]. Regarding the regulation of neuronal activity, exosomes have also been reported to deliver to neurons the enzymes involved in energy metabolism [38] (Fig 1).

In addition to the common canonical markers (Table 1), neuron-derived exosomes (NDE) contain the specific adhesion molecules NCAM (Neural Cell Adhesion Molecule) and CD171 or L1CAM (L1 Cell Adhesion Molecule), which were used initially by Dr Edward Goetzl' group to detect NDE in the plasma from a patient at the pre-clinical stage of AD ([39]; for review, see [40]; see also other contributions by Dr Goetzl and his team cited in this review). In addition, NDE contain lipid raft protein flotillin-2, sub-units of $\alpha$-amino-3-hydroxy-5methyl-isoxazolepropionic acid receptors (AMPARs) of glutamate and MicrotubuleAssociated Protein 1B (MAP-1B). Their cargo typically contains proteins involved in synaptic neurotransmission like synaptogamin and synaptophysin, among others [40,41]. Interestingly, it has been recently demonstrated that exosomes released from cortical neurons upon activation of glutamatergic synapses bind selectively to other neurons instead of being internalized by glial cells [42] thus underscoring the molecular substrate for neuron-to-neuron communication via exosomes.

Astrocyte-derived exosomes (ADE) cargo is enriched in GFAP (Glial Acidic Fibrillary Protein), Glutamine Synthetase (GlySyn), FGF2 (Fibroblast Growth Factor-2), VEGF 
(Vascular Endothelial Growth Factor) and extracellular matrix protein endostatin. Synapsin-1 is also comprised in the ADE cargo reflecting the role of astrocytes in synaptic neurotransmission [41]. In addition, the components of amyloidogenic pathway (A $\beta P P$, BACE1, $\gamma$-secretase) have recently been identified in ADE [43] thus suggesting that in pathological conditions, ADE can contribute to amyloidogenic pathway (see next Section: Pathological role of exosomes in neurodegenerative diseases: focus on AD).

Oligodendrocytes-derived exosomes (ODE) carry the cargo containing myelin-associated proteins (proteolipids and glycoproteins) and oligodendrocyte-specific cyclic-nucleotide phosphodiesterase (CNP) [44], required for the phospho-diester hydrolysis of the 2'3'-cyclic nucleotide to 2'-nucleotide during myelin biosynthesis. ODE play a major physiological role in neuron protection against the adverse effects of the transient increase in synaptic glutamate concentration in the course of neurotransmission. The evidence supporting such role of ODE comes from elegant studies using neuron/oligodendrocyte co-cultures allowing exclusively for exchange of the particles with a diameter lower than $1 \mu \mathrm{m}$ [45]. Furthermore, via their capacity to transfer super-oxide dismutase (SOD) and catalase to neurons, ODE participate in the control of neuronal oxidative stress [46].

In addition to the markers common to all exosomes (Table 1) and non-specific cargo proteins shared with dendritic cell- and B lymphocyte-derived exosomes (e.g. tetraspannins, chaperons...), the cargo of microglia-derived exosomes (MDE) contain some specific proteins such as aminopeptidase CD13 [47]. Reminiscent of physiological roles of microglia, MDE are involved in the control of neurite outgrowth, coordination of the innate immune response in the brain and modulation of neuronal activity [38]. Regarding the modulation of neuronal activity, it has been demonstrated that MDE can increase miniature Excitatory Post-Synaptic Potential (mEPSP) via selective enhancing the sphingolipid metabolism to control synaptic release of neurotransmitter containing synaptic vesicles [48]. 


\section{PATHOLOGICAL ROLE OF EXOSOMES IN NEURODEGENERATIVE DISEASES: FOCUS ON AD}

Understanding the role of exosomes in the pathophysiology of neurodegenerative diseases is only beginning to emerge. The study of the underlying mechanisms is complicated by the fact that exosomes may play a complex role in the pathogenesis of these diseases. It has thus been suggested that exosomes may play a dual role: i) beneficial by both promoting the clearance of toxic proteins from the cytoplasm of affected donor neurons and ii) deleterious by participating in spreading diseases via delivering these toxic proteins to the healthy recipient cells $[38,41,49,50]$. Moreover, in the context of challenging conditions (e.g. oxidative stress and related ROS induction, hypoxia, hypoglycemia, that all appear as common denominator of neurodegenerative diseases), it is likely that the failure of the physiological functions of exosomes may be involved. Besides, frequent dysfunction of the pathways (e.g. ubiquitinproteasome, autophagy, lysosomes...) implicated in degradation of neurotoxic proteins led to a new hypothesis in which exosomes play a central role. According to this new hypothesis, accumulation of the neurotoxic proteins can be compensated by increased biogenesis and release of exosomes when other degradation pathways failed. The alteration in endo-lysosomal pathway which may precede the onset of neurodegenerative disease for years, is in line with this attractive hypothesis [49]. In the next section, we will focus on the relevant issues in this context concerning AD. Putative involvement of exosomes in other neurodegenerative disorders such as Parkinson disease, fronto-temporal lobe dementia, Huntington $[41,49]$ and Amyotrophic-Lateral Sclerosis [50] is beyond the scope of this review and was discussed in detail in indicated recent reports.

\section{Exosomes in AD pathogenesis}


Among the neurotoxic proteins involved in neurodegenerative diseases, the role of exosomes in clearance and spread of $\mathrm{A} \beta$ and Tau in AD has been extensively studied. Thus, it has been reported that the enlargement of exosomal compartment in pyramidal neurons of the neocortex and the presence of $A \beta$ in NDE sorted from the plasma of AD patients could be detected up to 10 years before the onset of the clinical symptoms (for recent review, see [49]). In addition, exosomal markers were found to be enriched in $A \beta$-plaques of post-mortem $A D$ brains [51]. Besides, exosome production decreases in old AD mice, further suggesting that downregulation of exosomes may be related to increased plaque deposition and $\mathrm{AD}$ pathogenesis [52]. Interestingly, the presence of AD-related APOE isoform $\varepsilon 4$ compromises exosomal biogenesis and secretion [53], thus suggesting that the impairment of toxic protein clearance via exosomal route may indeed contribute to AD pathogenesis, in line with the recent hypothesis [54]. The involvement of exosomes in the spread of $A \beta$ and Tau proteins will be discussed in the next section because exosomes can indirectly control synaptic activity. Hence, by controlling the content of these proteins in the brain parenchyma, which in turn impacts the synaptic activity ([6,52]; see also the end of subsection Main hallmarks of AD pathogenesis), exosomes can contribute to the regulation of synaptic and neuronal functions.

\section{Role of exosomes in Aß and Tau clearance and spread}

Binding of $\mathrm{A} \beta$ to $\mathrm{NDE}$ through glycosphingolipid glycans or cellular prion protein $\left(\mathrm{PrP}^{\mathrm{C}}\right)$ on the extracellular vesicle surface may serve to remove extracellular $A \beta[49,55]$. A recent study has explicitly demonstrated the association between $\mathrm{A} \beta$ and exosomes by identifying a fraction of $\mathrm{A} \beta^{+} / \mathrm{CD} 68^{+}$double-positive exosomes in $\mathrm{AD}$ plasma samples [56]. Such capacity of exosomes to trap extracellular $\mathrm{A} \beta$ may promote its clearance by microglia. In agreement, exogenously added, labeled exosomes were found to colocalize with lysosomal/late endosomal markers (e.g. Lamp1) in the cytoplasm of the cultured microglia cells [54]. Moreover, in addition to their capacity to directly promote $\mathrm{A} \beta$ clearance by uptake and subsequent lysosomal 
digestion, microglia can contribute to this process indirectly. Thus, adding mixture of NDE and $A \beta$ to primary cultures of cortical neurons promotes formation of $A \beta$ fibrils in the extracellular space at the expense of toxic soluble oligomers. The NDE-associated fibrillar A $\beta$ is more prone to microglia uptake by a mechanism which depends on phospholipid expression and activity of sphingolipid-metabolizing enzymes on the surface of exosomes. This mode of exosomemediated uptake of fibrillar $A \beta$ appears immunologically silent, in contrast to direct ingestion of $A \beta$ by microglia [57]. Of note, the lipid expression at the surface of exosomes may be crucial for $A \beta$ clearance. Indeed, ADE express less glycosphingolipids than NDE and bind to A $\beta$ with lower affinity than NDE [52].

Besides $\mathrm{A} \beta$, exosomes can carry A $\beta \mathrm{PP}$ and its metabolites, such as CTF fragments [58]. In this light, AD-associated mutations in both A $\mathrm{PP}$ and PS1 have been correlated with impairment of endo-lysosomal pathway. It has been though hypothesized that lysosomal dysfunction in neurons yields increase in AßPP-CTFs in their endosomal compartment, which in turn triggers endosomal-lysosomal dysfunctions yielding a vicious feed-forward loop of amplification [59].

As already discussed, NDE isolated from blood, CSF and culture medium of cellular lines overexpressing $\mathrm{A} \beta$, all contain different (oligomeric and fibrillar) forms of $\mathrm{A} \beta$ (see [49] for review). In a recent elegant study, Sardar Sinha and colleagues demonstrated that exosomes isolated form human AD brain can be transferred from neuron-to-neuron in SH-SY5Y cell line and human induced pluripotent stem cells (iPSC). When biogenesis, secretion or uptake of NDE coming from AD patients was inhibited in cultured donor cells, the spread of $\mathrm{A} \beta$ oligomers and their toxicity in recipient cells were decreased too [55]. Interestingly, by using either coverslips (allowing for direct contact between neurites of donor and recipient cells) or transwell system (where no neuritic contact is possible) to grow recipient cells, these authors demonstrated that 
NDE-mediated A $\beta$ transfer does not require direct neuritic contact, although the transfer is more efficient when such contact is possible [55].

The mechanisms behind Tau secretion and spread via exosomes have been less studied in the past than those relevant for $\mathrm{A} \beta$. It is however known for a while that Tau can be secreted via exosomes from Tau-overexpressing neuronal cell lines (reviewed in [49]). Similar to A $\beta$, NDE from AD patients display up to 20 -fold increase in pathology-related Tau phosphorylation at threonine-181 and serine-396, as compared to Tau in NDE isolated form neurologically normal, age-matched controls. In addition, the level of threonine 181-hyperphosphorylated Tau is higher in NDE isolated from AD patients at late stages of pathology than in prodromal MCI subjects, in agreement with the proposed causal role of exosomes in the onset and progression of neurodegenerative diseases, including $\mathrm{AD}[49,50]$.

Remarkably, using neuronally-differentiated human iPSC, it has been demonstrated that exosomes containing AD-related pTau remain aggregation-competent after transfer into the recipient neuron-differentiated iPSC [60]. In an analogous approach, neuronally-differentiated human iPSC, further engineered to express repeat domain of Tau P301L and V337M mutations, were used to generate NDE. After subsequently transferring these NDE into the hippocampus of the wild-type mice, Winston and collaborators reported Tau inclusions, increase in pTau and extensive neurite degeneration in the recipient brain [61] thus explicitly demonstrating spread of Tau pathology via EVs. Most importantly, EVs secreted by neuronally-differentiated human iPSC coming from a patient with FAD and harboring an A246E mutations in PS1 encoding gene, triggered increased Tau expression and aberrant phosphorylation in vivo after intrahippocampal injection in wild-type mice [62]. In addition to providing further evidence for the seeding capacity of AD brain-derived EVs, this study brought the first in vivo demonstration of the possible link between amyloid and Tau pathology in which EVs may play a critical role $[62]$. 
Altogether, these recent studies suggest that exosomes might be among key mediators of pathogenic progression related to $\mathrm{A} \beta$ and Tau spread in $\mathrm{AD}$ (Figure 1).

\section{Putative role of exosomes in the control of synaptic activity}

There are currently only a few published studies in which the role of exosomes in the control of synaptic activity has been assessed directly. Indeed, the majority of studies in this context assessed the content of pre- and post-synaptic proteins in the cargo of NDE sorted from plasma of AD patients. These studies are concordant in terms of reporting the presence of synaptic proteins in NDE that probably reflects the synaptic loss. For instance, Goetzl and collaborators reported that the NDE content of pre-synaptic proteins pentraxin- 2 and neurexin $2 \alpha$ and their post-synaptic ligands glutamate receptor AMPA4 and neuroligin-1, respectively, decreases progressively with advancement of AD pathology [63]. Because these two ligand-receptor pairs are expressed specifically at excitatory synapses, and, given that the observed decline in the level of AMPA4 in NDE was further positively correlated with cognitive dysfunction [63], it is likely that NDE containing excitatory synapse-specific receptors (i.e. AMPA4) may be associated with the regulation of the relevant synaptic activity, even if in fine, they reflect the failure of this regulation yielding synaptic loss.

In a more direct approach, intra-cerebroventricular infusion of exosomes derived from either neuroblastoma cell line N2a or human CSF from healthy donors, could counteracts LTP impairment induced by subsequent infusion of soluble $A \beta$ species (obtained either by oligomerization of synthetic $\mathrm{A} \beta$ or purified from human $\mathrm{AD}$ brain) [64]. The observed protective effect of exosomes against synaptic toxicity of $A \beta$ was attributed to the sequestering and immobilization of $A \beta$ on the surface of exosomes [64].

Regarding the modulation of synaptic activity, it has been furthermore demonstrated that MDE can increase mEPSP via selectively enhancing the sphingolipid metabolism to control 
synaptic release of neurotransmitter-containing synaptic vesicles [48]. These data point to an additional, exosome-dependent mechanism for regulation of neuronal activity by microglia.

Interestingly, a recent study reported that EV derived from the bone marrow Mesenchymal Stem Cells (MSCs) exert protective effects on cultured primary hippocampal neurons exposed to A $\beta$-induced synaptic damage [65]. Besides, the protective effect of MSC-derived EVs encompassed also $\mathrm{A} \beta$-induced oxidative stress via $\mathrm{EV}$-mediated catalase delivery to the recipient neurons. MSC-mediated rescue from A $\beta$-triggered decrease in post-synaptic density protein 95 (PSD95) and pre-synaptic marker synaptophysin was explicitly demonstrated by coculturing primary hippocampal neurons and MSCs in the transwell system which allows for inter-cellular communication exclusively by soluble factors [65]. These findings were further extended by demonstrating that in vitro beneficial effects of MSC-derived EVs involve also inhibition of nitrosative stress by preventing A $\beta$-induced iNOS induction [66]. Such beneficial effects of MSC-derived EVs were in addition confirmed in vivo, by intra-cerebroventricular injection of MSC-derived EVs in APP/PS1 mouse model. This manipulation could efficiently alleviate the impairment of both $A \beta$-related pre-synaptic function, as attested by rescue of EPSP, and memory-related LTP which was further correlated with improvement of cognitive performance in new-object recognition and Morris water-maze tests [66].

In addition to the above discussed in situ impact of EVs (including exosomes) generated by the cells of the CNS (neurons and microglia, but also astrocytes) or provided exogenously by intracerebral injection, the peripheral-born EVs may hypothetically also contribute to the control of synaptic activity. This hypothesis is based on the analogy to EVs derived in the peripheral circulation from immune cells that are known to vehicle immunoregulatory molecules [67]. Thus, EVs secreted during peripheral inflammatory responses are thought to promote inflammation in endothelial cells, neutrophils, hepatocytes, macrophages, and monocytes via different mechanisms. These mechanisms include delivery of inflammasome's 
component neprylisine (e.g. NLRP3), pro-inflammatory cytokines (IL-1 $\beta$, TNF $\alpha$, IL-6, IL-8, INF- $\gamma \ldots$...) and chemokines [68], induction of prostaglandins or lipid-inflammatory mediators, to name a few [67]. As BBB is permeable to EVs, they may penetrate the brain and contribute to impairment of synaptic activity by triggering neuroinflammation. The latter could be in turn related to the cross-talk between systemic and CNS inflammation which is currently well recognized, although the underlying mechanisms remain poorly understood [69]. Of note, recent evidence suggests that circulating peripheral EVs may be underlying this cross-talk [70]. In agreement with this hypothesis, a pioneer study by Li and colleagues demonstrated last year that exosomes isolated from the serum of endotoxin-treated mice and transferred to naive recipient mice by i.v. injection, induce dramatic microglia and moderate astrocyte activation which was accompanied by the induction of TNF $\alpha$ and IL-6 transcripts, and pro-inflammatory microRNAs including miR-155, in both blood and brain [71]. Relevantly, the capacity of proinflammatory cytokines to regulate synaptic and neuronal functions is currently well recognized $[72]$.

Indirect, neuroinflammation-mediated, contribution of exosomes to the control of synaptic activity

As already discussed in the section dealing with Complexity of $A D$, microglia play a central role in neuroinflammation based on their capacity to produce immunomodulatory cytokines/chemokines [14] to subsequently impact neuronal activity [72], but also by sensing the neuronal activity in response to these immune mediators. Among the most studied underlying neuron-microglia interactions, there is the binding of ligands CD200, fractalkine (CX3CL1) and CCL2 expressed by neurons with their cognate microglia receptors CD200R, CXCL1R and CCL2R, respectively. Of note, CD200, CCL2 and CX3CL1 were identified respectively in neuroblastoma-, MSC- and fibroblast-derived EVs, thus strongly suggesting that the interaction of these ligands carried by EVs may impact neuron-microglia interactions. Such 
impact could translate into release from the inhibitory tonus that neurons exert on microglia to keep it in a homeostatic state (reviewed in [41]). In this light, identification of TGF- $\beta$ in neuroblastoma-derived EVs [73] is of particular importance, given that this growth factor plays a central role in the control of homeostatic phenotype of microglia [18].

Besides, EVs derived from microglia in inflammatory environment display cargo content which is distinct from the one in EVs derived from homeostatic microglia. Thus, it has been reported that EVs generated in the inflammatory conditions contain pro-inflammatory cytokines TNF $\alpha$, IL-1 $\beta$ and IL6 as well as miRNA (e.g. miR-155) (for recent review, see [74]). In particular, miRNAs in EVs shaded from inflammatory microglia may impact the expression of synaptic proteins in recipient neurons yielding synaptic dysfunction and loss [75] thus pointing to putative role of MDE in the control of synaptic activity. Most importantly, such MDE coming from the inflammatory environment may further trigger activation of additional microglia and astrocytes, and though contribute to implementing neuroinflammation [41]. Moreover, the expression of pro-inflammatory cytokines TNF $\alpha$, IL-1 $\beta$ and IL6 is higher in ADE coming from AD than age-matched neurologically normal subjects [76]. Glia EVs containing cytokines appear particularly important in terms of the role that cytokines exert in the control of synaptic activity via, for instance, synaptic up-scaling $[72,77,78]$.

Moreover, ADE obtained from plasma of AD patients contain higher level of complement proteins, including $\mathrm{C} 3$. Given that: i) genetic inhibition of $\mathrm{C} 3$ rescues the age-related decline in synaptic function as assessed by EPSP recording and quantification of pre- and post-synaptic proteins expression [79] and ii) reported capacity of $\mathrm{A} \beta$ to trigger $\mathrm{C} 3$ production by astrocytes [80], it is plausible that $\mathrm{A} \beta$ sequestration and secretion via $\mathrm{ADE}$ could corroborate further impairment $A \beta$-mediated synaptic dysfunction.

Circulating exosomes: diagnostic markers and read-out for monitoring of AD progression and treatment? 
From the evidence discussed in the previous sections it clearly appears that plasma EVs may become useful diagnostic markers for AD. Indeed, EVs (including exosomes) carry toxic proteins (e.g. A $\beta$, Tau... [51,60]) or intracellular components (e.g. lysosomal proteins, HSP70, ubiquitinylated proteins) whose levels differ between patients and control subjects [81]). These alterations are detectable in plasma up to 10 years before the clinical onset of the disease [81], thus pointing to EVs as attractive candidates for early and more reliable AD diagnosis. In agreement, the level of specific proteins such as Advanced Glycation End product (AGE) in the plasma exosomes was successfully used to differentiate early from moderate stage of AD $[82]$.

EVs could also be used as targets for development of new therapeutic approaches aimed on neuroprotection by, for instance, boosting the microglia capacity to generate EVs involved in clearance of $A \beta$ and Tau [38] or by providing healthy EVs to locally alleviate neurodegeneration by stimulating neurogenesis [59]. In this regard, use of MSC-derived EVs may turn to be particularly promising. In the work published in 2017 , Cui and coworkers reported that EVs coming from MSCs and i.v. injected bimonthly for 4 months to 7 months-old APP/PS1 mice reduced plaque deposition and cerebral A $\beta$ load, microglia and astrocyte activation and pro-inflammatory cytokines TNF $\alpha$ and IL-1 $\beta$. These alterations were concomitant with increase in anti-inflammatory cytokines IL-4 and IL-10 and improved cognitive performance. Interestingly, all these beneficial effects were increased if EVs were derived from MSCs cultured in hypoxia conditions [83]. These data are of paramount importance since they bring the pre-clinical proof of concept for the efficacy of using EVs for the treatment of $\mathrm{AD}$-like pathology in mice at the overt stage of the disease.

\section{CONCLUSIONS}


In spite of the great progress made during the recent years to diagnose $\mathrm{AD}$ earlier and more accurately, diagnosis is still disclosed relatively late. Identification of new biomarkers, notably those that might be detectable during the stage preceding the MCI, i.e. Subjective Cognitive Impairment (SCI), is urgently needed (SCI in contrast to $\mathrm{MCI}$, which is considered as prodromal stage of $\mathrm{AD}$ [7], corresponds to pre-clinical stage of $\mathrm{AD}$ ). In this review, we discussed the recent knowledge indicating that exosome hold the potential to become such early diagnostic markers for at least two main reasons. First, brain-derived exosomes are accessible non-invasively from peripheral circulation since they can cross the BBB. Second, exosomes reflect the function of neurons and glia and their communication, and more specifically the impairment of synaptic transmission. This property of exosomes is crucial considering synaptic dysfunctions as the earliest correlates of AD-related cognitive impairment [4]. Of utmost importance, there is currently no available method to directly assess the synaptic dysfunction in humans. The latter is further strengthening the need for future research allowing for clinical translation of the pre-clinical proof-of-concept for use of exosomes as early diagnostic tool.

In addition to their potential interest for early diagnosis, exosomes, and more precisely the content of their cargo, may be useful to discriminate between different stages of AD [82]. According to the current state-of-the-art, it appears that exosomes' involvement in clearance of neurotoxic proteins such as $\mathrm{A} \beta$ and $\mathrm{pTau}($ e.g. $[51,60])$, may be exploited as a strategy to delay the onset and progression of AD. Obviously, many challenges remain to be solved prior to such new therapeutic approaches. For instance, how to ascertain that exosomes loaded with the neurotoxic proteins would enter degradation pathways, rather than escape and serve as vectors for spreading these proteins?

But maybe the most promising perspective in this new field of exosomal biology consists in using these small vesicles to rescue the AD-related impairments of synaptic activity and subsequent cognitive impairment $[65,66]$. The small size, capacity to cross the BBB and the 
fact that exosomes are recognized by the immune system as "self" provide the interesting properties for such therapeutic purposes. Encouraging results, obtained in pre-clinical setting by using exosomes obtained from the healthy donor cells prepared in basal [59] or challenging (e.g. hypoxia) [83] conditions, provide an exciting perspective. Indeed, these recent data suggest that exosomes maybe modified for therapeutic purposes and that such "augmented" exosomes maybe then targeted to the cells expressing the receptors for the ligands that they bear at their surface. Even more, the expression of the ligands on the surface of exosomes maybe engineered to fit the expression of the receptors on the cells that are to be targeted. This approach may open the interesting avenues for the treatment of $\mathrm{AD}$, that combined with putative new exosomes-based diagnostic biomarkers should significantly help advancing the perspective of personalized medicine for earlier diagnosis and more efficient treatments of AD.

\section{CONFLICT OF INTEREST}

The authors have no conflict of interest to report.

\section{ACKNOWLEDGMENTS}

We thank Drs Guillaume Dorothée (INSERM, U938, Paris, France), Charles Ramassamy (INRS, Institut Armand-Frappier, Laval, QC, Canada) and Isabelle Aubert (University of Toronto, Toronto, ON, Canada) for constructive suggestions. We would also like to acknowledge the institutional support from Centre de Recherche Scientifique (CNRS) to SK and Centre de Recherche St. Antoine (CRSA) to HC.

\section{REFERENCES}

[1] Selkoe DJ, Hardy J (2016) The amyloid hypothesis of Alzheimer's disease at 25 years. EMBO Mol Med 8, 595-608. 
[2] Krantic S (2017) Editorial: From Current Diagnostic Tools and Therapeutics for Alzheimer's Disease Towards Earlier Diagnostic Markers and Treatment Targets. Curr Alzheimer Res 14, 2-5.

[3] Vossel KA, Ranasinghe KG, Beagle AJ, Mizuiri D, Honma SM, Dowling AF, Darwish SM, Van Berlo V, Barnes DE, Mantle M, Karydas AM, Coppola G, Roberson ED, Miller BL, Garcia PA, Kirsch HE, Mucke L, Nagarajan SS (2016) Incidence and Impact of Subclinical Epileptiform Activity in Alzheimer's Disease. Ann Neurol 80, 858-870.

[4] Palop JJ, Mucke L (2010) Amyloid-beta-induced neuronal dysfunction in Alzheimer's disease: from synapses toward neural networks. Nat Neurosci 13, 812-818.

[5] Li S, Jin M, Koeglsperger T, Shepardson NE, Shankar GM, Selkoe DJ (2011) Soluble $\mathrm{A} \beta$ oligomers inhibit long-term potentiation through a mechanism involving excessive activation of extrasynaptic NR2B-containing NMDA receptors. J Neurosci 31, 66276638.

[6] Tracy TE, Gan L (2018) Tau-mediated synaptic and neuronal dysfunction in neurodegenerative disease. Curr Opinion Neurobiol 51, 134-138.

[7] Tönnies E, Trushina E (2017) Oxidative Stress, Synaptic Dysfunction, and Alzheimer's Disease. J Alzheimers Dis 57, 1105-1121.

[8] Dubois B (2018) The Emergence of a New Conceptual Framework for Alzheimer's Disease. J Alzheimers Dis 62, 1059-1066.

[9] Lane CA, Hardy J, Schott JM (2018) Alzheimer's disease. Eur. J. Neurol. 25, 59-70.

[10] McQuade A, Blurton-Jones M (2019) Microglia in Alzheimer's Disease: Exploring How Genetics and Phenotype Influence Risk. J Mol Biol 431, 1805-1817.

[11] Estes ML, McAllister AK (2014) Alterations in immune cells and mediators in the brain: it's not always neuroinflammation! Brain Pathol 24, 623-630.

[12] Monsonego A, Zota V, Karni A, Krieger JI, Bar-Or A, Bitan G, Budson AE, Sperling $\mathrm{R}$, Selkoe DJ, Weiner HL (2003) Increased T cell reactivity to amyloid $\beta$ protein in older humans and patients with Alzheimer disease. J Clin Invest 112, 415-422.

[13] Dansokho C, Ait Ahmed D, Aid S, Toly-Ndour C, Chaigneau T, Calle V, Cagnard N, Holzenberger M, Piaggio E, Aucouturier P, Dorothée G (2016) Regulatory T cells delay disease progression in Alzheimer-like pathology. Brain 139, 1237-1251.

[14] Perry VH, Holmes C (2014) Microglial priming in neurodegenerative disease. Nat Rev Neurol 10, 217-224.

[15] Zenaro E, Pietronigro E, Della Bianca V, Piacentino G, Marongiu L, Budui S, Turano E, Rossi B, Angiari S, Dusi S, Montresor A, Carlucci T, Nanì S, Tosadori G, Calciano L, Catalucci D, Berton G, Bonetti B, Constantin G (2015) Neutrophils promote Alzheimer's disease-like pathology and cognitive decline via LFA-1 integrin. Nat Med 21, 880-886.

[16] Calsolaro V, Edison P (2016) Neuroinflammation in Alzheimer's disease: Current evidence and future directions. Alzheimers Dem 12, 719-732.

[17] Hamelin L, Lagarde J, Dorothée G, Leroy C, Labit M, Comley RA, de Souza LC, Corne H, Dauphinot L, Bertoux M, Dubois B, Gervais P, Colliot O, Potier MC, Bottlaender M, Sarazin M, Clinical IMABio3 team (2016) Early and protective microglial activation in Alzheimer's disease: a prospective study using 18F-DPA-714 PET imaging. Brain 139, 1252-1264.

[18] Butovsky O, Weiner HL (2018) Microglial signatures and their role in health and disease. Nat Rev Neurosci 19, 622-635.

[19] Wagner LK, Gilling KE, Schormann E, Kloetzel PM, Heppner FL, Krüger E, Prokop S (2017) Immunoproteasome deficiency alters microglial cytokine response and 
improves cognitive deficits in Alzheimer's disease-like APPPS1 mice. Acta Neuropathol Commun 5, 52, doi: 10.1186/s40478-017-0453-5.

[20] Cavanagh C, Colby-Milley J, Bouvier D, Farso M, Chabot J-G, Quirion R, Krantic S (2013) $\beta C T F$-correlated burst of hippocampal TNF $\alpha$ occurs at a very early, pre-plaque stage in the TgCRND8 mouse model of Alzheimer's disease. J Alzheimers Dis 36, 233-238.

[21] Cavanagh C, Tse YC, Nguyen H-B, Krantic S, Breitner JCS, Quirion R, Wong TP (2016) Inhibiting tumor necrosis factor- $\alpha$ before amyloidosis prevents synaptic deficits in an Alzheimer's disease model. Neurobiol Aging 47, 41-49.

[22] Walker LC (2018) Prion-like mechanisms in Alzheimer disease. Handb Clin Neurol 153, 303-319.

[23] Clavaguera F, Tolnay M, Goedert M (2017) The Prion-Like Behavior of Assembled Tau in Transgenic Mice. Cold Spring Harb Perspect Med 7, a024372, doi: 10.1101/cshperspect.a024372.

[24] Lemere CA, Lopera F, Kosik KS, Lendon CL, Ossa J, Saido TC, Yamaguchi H, Ruiz A, Martinez A, Madrigal L, Hincapie L, L JCA, Anthony DC, Koo EH, Goate AM, Selkoe DJ, V JCA (1996) The E280A presenilin 1 Alzheimer mutation produces increased A 342 deposition and severe cerebellar pathology. Nat Med 2, 1146-1150.

[25] Bateman RJ, Xiong C, Benzinger TLS, Fagan AM, Goate A, Fox NC, Marcus DS, Cairns NJ, Xie X, Blazey TM, Holtzman DM, Santacruz A, Buckles V, Oliver A, Moulder K, Aisen PS, Ghetti B, Klunk WE, McDade E, Martins RN, Masters CL, Mayeux R, Ringman JM, Rossor MN, Schofield PR, Sperling RA, Salloway S, Morris JC, Dominantly Inherited Alzheimer Network (2012) Clinical and biomarker changes in dominantly inherited Alzheimer's disease. New Engl J Med 367, 795-804.

[26] Nath S, Agholme L, Kurudenkandy FR, Granseth B, Marcusson J, Hallbeck M (2012) Spreading of Neurodegenerative Pathology via Neuron-to-Neuron Transmission of $\beta$ Amyloid. J Neurosci 32, 8767-8777.

[27] Eisele YS, Duyckaerts C (2016) Propagation of Aß pathology: hypotheses, discoveries, and yet unresolved questions from experimental and human brain studies. Acta Neuropathol 131, 5-25.

[28] Bolós M, Perea JR, Avila J (2017) Alzheimer's disease as an inflammatory disease. Biomol Concepts 8, 37-43.

[29] van Niel G, D'Angelo G, Raposo G (2018) Shedding light on the cell biology of extracellular vesicles. Nat Rev Mol Cell Biol 19, 213-228.

[30] Théry C, Witwer KW, Aikawa E, Alcaraz MJ, Anderson JD, Andriantsitohaina R, Antoniou A, Arab T, Archer F, Atkin-Smith GK, Ayre DC, Bach J-M, Bachurski D, Baharvand H, Balaj L, Baldacchino S, Bauer NN, Baxter AA, Bebawy M, Beckham C, Bedina Zavec A, Benmoussa A, Berardi AC, Bergese P, Bielska E, Blenkiron C, Bobis-Wozowicz S, Boilard E, Boireau W, Bongiovanni A, Borràs FE, Bosch S, Boulanger CM, Breakefield X, Breglio AM, Brennan MÁ, Brigstock DR, Brisson A, Broekman ML, Bromberg JF, Bryl-Górecka P, Buch S, Buck AH, Burger D, Busatto S, Buschmann D, Bussolati B, Buzás EI, Byrd JB, Camussi G, Carter DR, Caruso S, Chamley LW, Chang Y-T, Chen C, Chen S, Cheng L, Chin AR, Clayton A, Clerici SP, Cocks A, Cocucci E, Coffey RJ, Cordeiro-da-Silva A, Couch Y, Coumans FA, Coyle B, Crescitelli R, Criado MF, D'Souza-Schorey C, Das S, Datta Chaudhuri A, de Candia P, De Santana EF, De Wever O, Del Portillo HA, Demaret T, Deville S, Devitt A, Dhondt B, Di Vizio D, Dieterich LC, Dolo V, Dominguez Rubio AP, Dominici M, Dourado MR, Driedonks TA, Duarte FV, Duncan HM, Eichenberger RM, Ekström K, El Andaloussi S, Elie-Caille C, Erdbrügger U, Falcón-Pérez JM, Fatima F, Fish JE, Flores-Bellver M, Försönits A, Frelet-Barrand A, Fricke F, Fuhrmann G, Gabrielsson 
S, Gámez-Valero A, Gardiner C, Gärtner K, Gaudin R, Gho YS, Giebel B, Gilbert C, Gimona M, Giusti I, Goberdhan DC, Görgens A, Gorski SM, Greening DW, Gross JC, Gualerzi A, Gupta GN, Gustafson D, Handberg A, Haraszti RA, Harrison P, Hegyesi H, Hendrix A, Hill AF, Hochberg FH, Hoffmann KF, Holder B, Holthofer H, Hosseinkhani B, Hu G, Huang Y, Huber V, Hunt S, Ibrahim AG-E, Ikezu T, Inal JM, Isin M, Ivanova A, Jackson HK, Jacobsen S, Jay SM, Jayachandran M, Jenster G, Jiang L, Johnson SM, Jones JC, Jong A, Jovanovic-Talisman T, Jung S, Kalluri R, Kano S-I, Kaur S, Kawamura Y, Keller ET, Khamari D, Khomyakova E, Khvorova A, Kierulf P, Kim KP, Kislinger T, Klingeborn M, Klinke DJ, Kornek M, Kosanović MM, Kovács ÁF, Krämer-Albers E-M, Krasemann S, Krause M, Kurochkin IV, Kusuma GD, Kuypers S, Laitinen S, Langevin SM, Languino LR, Lannigan J, Lässer C, Laurent LC, Lavieu G, Lázaro-Ibáñez E, Le Lay S, Lee M-S, Lee YXF, Lemos DS, Lenassi M, Leszczynska A, Li IT, Liao K, Libregts SF, Ligeti E, Lim R, Lim SK, Linē A, Linnemannstöns K, Llorente A, Lombard CA, Lorenowicz MJ, Lörincz ÁM, Lötvall J, Lovett J, Lowry MC, Loyer X, Lu Q, Lukomska B, Lunavat TR, Maas SL, Malhi H, Marcilla A, Mariani J, Mariscal J, Martens-Uzunova ES, Martin-Jaular L, Martinez MC, Martins VR, Mathieu M, Mathivanan S, Maugeri M, McGinnis LK, McVey MJ, Meckes DG, Meehan KL, Mertens I, Minciacchi VR, Möller A, Møller Jørgensen M, Morales-Kastresana A, Morhayim J, Mullier F, Muraca M, Musante L, Mussack V, Muth DC, Myburgh KH, Najrana T, Nawaz M, Nazarenko I, Nejsum P, Neri C, Neri T, Nieuwland R, Nimrichter L, Nolan JP, Nolte-'t Hoen EN, Noren Hooten N, O'Driscoll L, O'Grady T, O'Loghlen A, Ochiya T, Olivier M, Ortiz A, Ortiz LA, Osteikoetxea X, Østergaard O, Ostrowski M, Park J, Pegtel DM, Peinado H, Perut F, Pfaffl MW, Phinney DG, Pieters BC, Pink RC, Pisetsky DS, Pogge von Strandmann E, Polakovicova I, Poon IK, Powell BH, Prada I, Pulliam L, Quesenberry P, Radeghieri A, Raffai RL, Raimondo S, Rak J, Ramirez MI, Raposo G, Rayyan MS, Regev-Rudzki N, Ricklefs FL, Robbins PD, Roberts DD, Rodrigues SC, Rohde E, Rome S, Rouschop KM, Rughetti A, Russell AE, Saá P, Sahoo S, Salas-Huenuleo E, Sánchez C, Saugstad JA, Saul MJ, Schiffelers RM, Schneider R, Schøyen TH, Scott A, Shahaj E, Sharma S, Shatnyeva O, Shekari F, Shelke GV, Shetty AK, Shiba K, Siljander PR-M, Silva AM, Skowronek A, Snyder OL, Soares RP, Sódar BW, Soekmadji C, Sotillo J, Stahl PD, Stoorvogel W, Stott SL, Strasser EF, Swift S, Tahara H, Tewari M, Timms K, Tiwari S, Tixeira R, Tkach M, Toh WS, Tomasini R, Torrecilhas AC, Tosar JP, Toxavidis V, Urbanelli L, Vader P, van Balkom BW, van der Grein SG, Van Deun J, van Herwijnen MJ, Van Keuren-Jensen K, van Niel G, van Royen ME, van Wijnen AJ, Vasconcelos MH, Vechetti IJ, Veit TD, Vella LJ, Velot É, Verweij FJ, Vestad B, Viñas JL, Visnovitz T, Vukman KV, Wahlgren J, Watson DC, Wauben MH, Weaver A, Webber JP, Weber V, Wehman AM, Weiss DJ, Welsh JA, Wendt S, Wheelock AM, Wiener Z, Witte L, Wolfram J, Xagorari A, Xander P, Xu J, Yan X, Yáñez-Mó M, Yin H, Yuana Y, Zappulli V, Zarubova J, Žèkas V, Zhang J-Y, Zhao Z, Zheng L, Zheutlin AR, Zickler AM, Zimmermann P, Zivkovic AM, Zocco D, Zuba-Surma EK (2018) Minimal information for studies of extracellular vesicles 2018 (MISEV2018): a position statement of the International Society for Extracellular Vesicles and update of the MISEV2014 guidelines. J Extracell Vesicles 7, 1535750, doi: 10.1101/cshperspect.a024372.

[31] Milane L, Singh A, Mattheolabakis G, Suresh M, Amiji MM (2015) Exosome mediated communication within the tumor microenvironment. J Control Release 219, 278-294.

[32] Kowal J, Arras G, Colombo M, Jouve M, Morath JP, Primdal-Bengtson B, Dingli F, Loew D, Tkach M, Théry C (2016) Proteomic comparison defines novel markers to 
characterize heterogeneous populations of extracellular vesicle subtypes. Proc Natl Acad Sci USA 113, E968-E977.

[33] Mulcahy LA, Pink RC, Carter DRF (2014) Routes and mechanisms of extracellular vesicle uptake. J Extracell Vesicles 3, 24641, doi: 10.3402/jev.v3.24641.

[34] Caruso Bavisotto C, Scalia F, Marino Gammazza A, Carlisi D, Bucchieri F, Conway de Macario E, Macario AJL, Cappello F, Campanella C (2019) Extracellular VesicleMediated Cell-Cell Communication in the Nervous System: Focus on Neurological Diseases. Int J Mol Sci 20, 434, doi: 10.3390/ijms20020434.

[35] Takahashi A, Okada R, Nagao K, Kawamata Y, Hanyu A, Yoshimoto S, Takasugi M, Watanabe S, Kanemaki MT, Obuse C, Hara E (2017) Exosomes maintain cellular homeostasis by excreting harmful DNA from cells. Nat Comm 8, 15287, doi: $10.1038 /$ ncomms 15287.

[36] Vlassov AV, Magdaleno S, Setterquist R, Conrad R (2012) Exosomes: current knowledge of their composition, biological functions, and diagnostic and therapeutic potentials. Biochim Biophys Acta 1820, 940-948.

[37] Lee S, Mankhong S, Kang J-H (2019) Extracellular Vesicle as a Source of Alzheimer's Biomarkers: Opportunities and Challenges. Int J Mol Sci 20, 1728, doi:10.3390/ijms2007172.

[38] Trotta T, Panaro MA, Cianciulli A, Mori G, Di Benedetto A, Porro C (2018) Microglia-derived extracellular vesicles in Alzheimer's Disease: A double-edged sword. Biochem Pharmacol 148, 184-192.

[39] Fiandaca MS, Kapogiannis D, Mapstone M, Boxer A, Eitan E, Schwartz JB, Abner EL, Petersen RC, Federoff HJ, Miller BL, Goetzl EJ (2015) Identification of preclinical Alzheimer's disease by a profile of pathogenic proteins in neurally derived blood exosomes: A case-control study. Alzheimers Dem 11, 600-607.e1, doi: 10.1016/j.jalz.2014.06.008.

[40] Mustapic M, Eitan E, Werner JK, Berkowitz ST, Lazaropoulos MP, Tran J, Goetzl EJ, Kapogiannis D (2017) Plasma Extracellular Vesicles Enriched for Neuronal Origin: A Potential Window into Brain Pathologic Processes. Front Neurosci 11, 278, doi: 10.3389/fnins.2017.00278.

[41] Delpech J-C, Herron S, Botros MB, Ikezu T (2019) Neuroimmune Crosstalk through Extracellular Vesicles in Health and Disease. Trends Neurosci 42, 361-372.

[42] Chivet M, Javalet C, Laulagnier K, Blot B, Hemming FJ, Sadoul R (2014) Exosomes secreted by cortical neurons upon glutamatergic synapse activation specifically interact with neurons. J Extracell Vesicles 3, 24722, doi: 10.3402/jev.v3.24722.

[43] Goetzl EJ, Mustapic M, Kapogiannis D, Eitan E, Lobach IV, Goetzl L, Schwartz JB, Miller BL (2016) Cargo proteins of plasma astrocyte-derived exosomes in Alzheimer's disease. FASEB J 30, 3853-3859.

[44] Krämer-Albers E-M, Bretz N, Tenzer S, Winterstein C, Möbius W, Berger H, Nave KA, Schild H, Trotter J (2007) Oligodendrocytes secrete exosomes containing major myelin and stress-protective proteins: Trophic support for axons? Proteomics Clin Appl 1, 1446-1461.

[45] Frühbeis C, Fröhlich D, Kuo WP, Amphornrat J, Thilemann S, Saab AS, Kirchhoff F, Möbius W, Goebbels S, Nave K-A, Schneider A, Simons M, Klugmann M, Trotter J, Krämer-Albers E-M (2013) Neurotransmitter-Triggered Transfer of Exosomes Mediates Oligodendrocyte-Neuron Communication. PLoS Biol 11, e1001604.

[46] Fröhlich D, Kuo WP, Frühbeis C, Sun J-J, Zehendner CM, Luhmann HJ, Pinto S, Toedling J, Trotter J, Krämer-Albers E-M (2014) Multifaceted effects of oligodendroglial exosomes on neurons: impact on neuronal firing rate, signal 
transduction and gene regulation. Philos Trans R. Soc Lond B Biol Sci 369, 20130510, doi: 10.1098/rstb.2013.0510.

[47] Potolicchio I, Carven GJ, Xu X, Stipp C, Riese RJ, Stern LJ, Santambrogio L (2005) Proteomic analysis of microglia-derived exosomes: metabolic role of the aminopeptidase CD13 in neuropeptide catabolism. J Immunol 175, 2237-2243.

[48] Antonucci F, Turola E, Riganti L, Caleo M, Gabrielli M, Perrotta C, Novellino L, Clementi E, Giussani P, Viani P, Matteoli M, Verderio C (2012) Microvesicles released from microglia stimulate synaptic activity via enhanced sphingolipid metabolism. EMBO J 31, 1231-1240.

[49] Watson LS, Hamlett ED, Stone TD, Sims-Robinson C (2019) Neuronally derived extracellular vesicles: an emerging tool for understanding Alzheimer's disease. $\mathrm{Mol}$ Neurodegen 14, 22, doi: 10.1186/s13024-019-0317-5.

[50] Ferrara D, Pasetto L, Bonetto V, Basso M (2018) Role of Extracellular Vesicles in Amyotrophic Lateral Sclerosis. Front Neurosci 12, 574, doi: 10.3389/fnins.2018.00574.

[51] Rajendran L, Honsho M, Zahn TR, Keller P, Geiger KD, Verkade P, Simons K (2006) Alzheimer's disease $\beta$-amyloid peptides are released in association with exosomes. Proc Natl Acad Sci USA 103, 11172-11177.

[52] Yuyama K, Sun H, Usuki S, Sakai S, Hanamatsu H, Mioka T, Kimura N, Okada M, Tahara H, Furukawa J, Fujitani N, Shinohara Y, Igarashi Y (2015) A potential function for neuronal exosomes: sequestering intracerebral amyloid- $\beta$ peptide. FEBS Lett 589, 84-88.

[53] Peng KY, Pérez-González R, Alldred MJ, Goulbourne CN, Morales-Corraliza J, Saito M, Saito M, Ginsberg SD, Mathews PM, Levy E (2019) Apolipoprotein E4 genotype compromises brain exosome production. Brain 142, 163-175.

[54] Fitzner D, Schnaars M, van Rossum D, Krishnamoorthy G, Dibaj P, Bakhti M, Regen T, Hanisch U-K, Simons M (2011) Selective transfer of exosomes from oligodendrocytes to microglia by macropinocytosis. J Cell Sci 124, 447-458.

[55] Sardar Sinha M, Ansell-Schultz A, Civitelli L, Hildesjö C, Larsson M, Lannfelt L, Ingelsson M, Hallbeck M (2018) Alzheimer's disease pathology propagation by exosomes containing toxic amyloid-beta oligomers. Acta Neuropathol 136, 41-56.

[56] Lim CZJ, Zhang Y, Chen Y, Zhao H, Stephenson MC, Ho NRY, Chen Y, Chung J, Reilhac A, Loh TP, Chen CLH, Shao H (2019) Subtyping of circulating exosomebound amyloid $\beta$ reflects brain plaque deposition. Nat Comm 10, 1144, doi: 10.1038/s41467-019-09030-2.

[57] Yuyama K, Sun H, Mitsutake S, Igarashi Y (2012) Sphingolipid-modulated Exosome Secretion Promotes Clearance of Amyloid- $\beta$ by Microglia. J Biol Chem 287, $10977-$ 10989.

[58] Miranda AM, Lasiecka ZM, Xu Y, Neufeld J, Shahriar S, Simoes S, Chan RB, Oliveira TG, Small SA, Di Paolo G (2018) Neuronal lysosomal dysfunction releases exosomes harboring APP C-terminal fragments and unique lipid signatures. Nat Comm 9, 1-16.

[59] Guix FX (2019) The interplay between aging-associated loss of protein homeostasis and extracellular vesicles in neurodegeneration. $J$ Neurosci Res 98, 262-283.

[60] Guix FX, Corbett GT, Cha DJ, Mustapic M, Liu W, Mengel D, Chen Z, Aikawa E, Young-Pearse T, Kapogiannis D, Selkoe DJ, Walsh DM (2018) Detection of Aggregation-Competent Tau in Neuron-Derived Extracellular Vesicles. Int J Mol Sci 19, 663, doi: 10.3390/ijms19030663.

[61] Winston CN, Aulston B, Rockenstein EM, Adame A, Prikhodko O, Dave KN, Mishra P, Rissman RA, Yuan SH (2019) Neuronal Exosome-Derived Human Tau is Toxic to Recipient Mouse Neurons in vivo. J Alzheimers Dis 67, 541-553. 
[62] Aulston B, Liu Q, Mante M, Florio J, Rissman RA, Yuan SH (2019) Extracellular Vesicles Isolated from Familial Alzheimer's Disease Neuronal Cultures Induce Aberrant Tau Phosphorylation in the Wild-Type Mouse Brain. J Alzheimers Dis 72, $575-585$.

[63] Goetzl EJ, Abner EL, Jicha GA, Kapogiannis D, Schwartz JB (2018) Declining levels of functionally specialized synaptic proteins in plasma neuronal exosomes with progression of Alzheimer's disease. FASEB J 32, 888-893.

[64] An K, Klyubin I, Kim Y, Jung JH, Mably AJ, O’Dowd ST, Lynch T, Kanmert D, Lemere CA, Finan GM, Park JW, Kim T-W, Walsh DM, Rowan MJ, Kim J-H (2013) Exosomes neutralize synaptic-plasticity-disrupting activity of $\mathrm{A} \beta$ assemblies in vivo. Mol Brain 6, 47, doi: 10.1186/1756-6606-6-47.

[65] de Godoy MA, Saraiva LM, de Carvalho LRP, Vasconcelos-Dos-Santos A, Beiral HJV, Ramos AB, Silva LR de P, Leal RB, Monteiro VHS, Braga CV, de Araujo-Silva CA, Sinis LC, Bodart-Santos V, Kasai-Brunswick TH, Alcantara C de L, Lima APCA, da Cunha-E Silva NL, Galina A, Vieyra A, De Felice FG, Mendez-Otero R, Ferreira ST (2018) Mesenchymal stem cells and cell-derived extracellular vesicles protect hippocampal neurons from oxidative stress and synapse damage induced by amyloid- $\beta$ oligomers. J Biol Chem 293, 1957-1975.

[66] Wang S-S, Jia J, Wang Z (2018) Mesenchymal Stem Cell-Derived Extracellular Vesicles Suppresses iNOS Expression and Ameliorates Neural Impairment in Alzheimer's Disease Mice. J Alzheimers Dis 61, 1005-1013.

[67] Cypryk W, Nyman TA, Matikainen S (2018) From Inflammasome to Exosome-Does Extracellular Vesicle Secretion Constitute an Inflammasome-Dependent Immune Response? Front Immunol 9, 2188, doi: 10.3389/fimmu.2018.02188.

[68] Chen T, Guo J, Yang M, Zhu X, Cao X (2011) Chemokine-Containing Exosomes Are Released from Heat-Stressed Tumor Cells via Lipid Raft-Dependent Pathway and Act as Efficient Tumor Vaccine. J Immunol 186, 2219-2228.

[69] Paouri E, Georgopoulos S (2019) Systemic and CNS Inflammation Crosstalk: Implications for Alzheimer's Disease. Curr Alzheimer Res 16, 559-574.

[70] Ridder K, Keller S, Dams M, Rupp A-K, Schlaudraff J, Turco DD, Starmann J, Macas J, Karpova D, Devraj K, Depboylu C, Landfried B, Arnold B, Plate KH, Höglinger G, Sültmann H, Altevogt P, Momma S (2014) Extracellular Vesicle-Mediated Transfer of Genetic Information between the Hematopoietic System and the Brain in Response to Inflammation. PLoS Biol 12, e1001874.

[71] Li JJ, Wang B, Kodali MC, Chen C, Kim E, Patters BJ, Lan L, Kumar S, Wang X, Yue J, Liao F-F (2018) In vivo evidence for the contribution of peripheral circulating inflammatory exosomes to neuroinflammation. $J$ Neuroinflammation $\mathbf{1 5}, 8$, doi: 10.1186/s12974-017-1038-8.

[72] Prieto GA, Cotman CW (2017) Cytokines and cytokine networks target neurons to modulate long-term potentiation. Cyt Growth Factor Rev 34, 27-33.

[73] Matias D, Balça-Silva J, da Graça GC, Wanjiru CM, Macharia LW, Nascimento CP, Roque NR, Coelho-Aguiar JM, Pereira CM, Dos Santos MF, Pessoa LS, Lima FRS, Schanaider A, Ferrer VP, Spohr TCL de S e, Moura-Neto V (2018)

Microglia/Astrocytes-Glioblastoma Crosstalk: Crucial Molecular Mechanisms and Microenvironmental Factors. Front Cell Neurosci 12, 235, doi10.3389/fncel.2018.00235.

[74] Paolicelli RC, Bergamini G, Rajendran L (2019) Cell-to-cell Communication by Extracellular Vesicles: Focus on Microglia. Neuroscience 405, 148-157.

[75] Prada I, Gabrielli M, Turola E, Iorio A, D’Arrigo G, Parolisi R, De Luca M, Pacifici M, Bastoni M, Lombardi M, Legname G, Cojoc D, Buffo A, Furlan R, Peruzzi F, Verderio 
C (2018) Glia-to-neuron transfer of miRNAs via extracellular vesicles: a new mechanism underlying inflammation-induced synaptic alterations. Acta Neuropathol 135, 529-550.

[76] Goetzl EJ, Schwartz JB, Abner EL, Jicha GA, Kapogiannis D (2018) High complement levels in astrocyte-derived exosomes of Alzheimer disease. Ann Neurol 83, 544-552.

[77] Stellwagen D, Malenka RC (2006) Synaptic scaling mediated by glial TNF-alpha. Nature 440, 1054-1059.

[78] Zhang R, Yamada J, Hayashi Y, Wu Z, Koyama S, Nakanishi H (2008) Inhibition of NMDA-induced outward currents by interleukin-1 $\beta$ in hippocampal neurons. Biochem Biophys Res Comm 372, 816-820.

[79] Shi Q, Colodner KJ, Matousek SB, Merry K, Hong S, Kenison JE, Frost JL, Le KX, Li S, Dodart J-C, Caldarone BJ, Stevens B, Lemere CA (2015) Complement C3-Deficient Mice Fail to Display Age-Related Hippocampal Decline. J Neurosci 35, 13029-13042.

[80] Lian H, Litvinchuk A, Chiang AC-A, Aithmitti N, Jankowsky JL, Zheng H (2016) Astrocyte-Microglia Cross Talk through Complement Activation Modulates Amyloid Pathology in Mouse Models of Alzheimer's Disease. J Neurosci 36, 577-589.

[81] Goetzl EJ, Boxer A, Schwartz JB, Abner EL, Petersen RC, Miller BL, Kapogiannis D (2015) Altered lysosomal proteins in neural-derived plasma exosomes in preclinical Alzheimer disease. Neurology 85, 40-47.

[82] Haddad M, Perrotte M, Landri S, Lepage A, Fülöp T, Ramassamy C (2019) Circulating and Extracellular Vesicles Levels of N-(1-Carboxymethyl)-L-Lysine (CML) Differentiate Early to Moderate Alzheimer's Disease. J Alzheimers Dis 69, 751-762.

[83] Cui G-H, Wu J, Mou F-F, Xie W-H, Wang F-B, Wang Q-L, Fang J, Xu Y-W, Dong YR, Liu J-R, Guo H-D (2017) Exosomes derived from hypoxia-preconditioned mesenchymal stromal cells ameliorate cognitive decline by rescuing synaptic dysfunction and regulating inflammatory responses in APP/PS1 mice. FASEB $J \mathbf{3 2}$, 654-668.

\section{FIGURE LEGEND}

Figure 1: Hypothetical involvement of the cross-talk between peripheral and brainderived exosomes in AD pathogenesis. EVs cross the $\mathrm{BBB}$ in both directions. By consequence, $\mathrm{AD}$ pathogenesis may be influenced by peripheral EVs transporting inflammatory factors, and generated for instance, by lymphocytes or gut microbiota. Circulatory EVs are able to reach the brain and impact glial and neuronal activity. It has been proposed that during the pre-symptomatic stage of $\mathrm{AD}$, EVs participate in $\mathrm{A} \beta$ clearance and maintain of neuronal and synaptic functions. However, during advanced stages of the disease, EVs may spread AD-related proteins (A $\beta$, pTau) and pro-inflammatory factors (TNF $\alpha$, IL-1 $\beta$, ROS...) through direct and indirect communications with the recipient cells. The propagation of toxic molecules by peripheral and brain-derived exosomes thus participates to 
neuroinflammation and neurodegeneration, and consistently to AD pathogenesis. Conversely, brain-derived exosomes can also cross the BBB and are detectable in the peripheral circulation. Analysis of their cargo may turn to be useful, non-invasively detectable diagnostic tool. 
Table 1: Tentative classification of extracellular vesicles (EVs) and exosomal markers. ISEV recommends characterizing EV/exosomes with three protein markers of EVs/exosomes, including at least: $i$ ) one transmembrane/lipid-bound protein, ii) one cytosolic protein and iii) at least one negative protein marker [33].

\begin{tabular}{|c|c|c|c|}
\hline \multirow[t]{2}{*}{ Markers } & \multirow{2}{*}{$\begin{array}{c}\text { Commons } \\
\text { Extracellular } \\
\text { vesicles \& } \\
\text { Exosomes }\end{array}$} & \multicolumn{2}{|c|}{ Specifics } \\
\hline & & Extracellular vesicles & Exosomes \\
\hline $\begin{array}{l}\text { Membrane } \\
\text { organizers }\end{array}$ & CD9, CD81 [29] & CD82 [29] & $\begin{array}{l}\text { CD13 [41] } \\
\text { CD9, CD63 [47] } \\
\text { CD81, CD53, CD37, } \\
\text { CD151, TSPAN6, } \\
\text { TSPAN8, Flotilin 1 and } \\
2 \text { [29] }\end{array}$ \\
\hline Lipids & $\begin{array}{l}\text { Phosphatidylserine, } \\
\text { sphingolipids [29] }\end{array}$ & $\begin{array}{l}\text { Phosphatidylethanolamine } \\
\text { [29] }\end{array}$ & $\begin{array}{l}\text { Phosphatidylserine, } \\
\text { cholesterol, ceramide } \\
\text { and other sphingolipids, } \\
\text { LBPA [29] }\end{array}$ \\
\hline $\begin{array}{c}\text { Chaperone } \\
\text { proteins }\end{array}$ & HSP70, HSP90 [29] & & \\
\hline $\begin{array}{l}\text { Biogenesis } \\
\text { factors }\end{array}$ & $\begin{array}{l}\text { ALIX, TSG101, } \\
\text { VPS4 [29] }\end{array}$ & ERK, PLD [29] & $\begin{array}{l}\text { FGF2 [41] } \\
\text { ALIX, TSG101, } \\
\text { syntenin, ubiquitin, } \\
\text { clathrin, VPS32, VPS4 } \\
\text { [29] }\end{array}$ \\
\hline $\begin{array}{l}\text { Intracellular } \\
\text { trafficking }\end{array}$ & $\begin{array}{l}\text { RAB GTPases, } \\
\text { annexins [29] }\end{array}$ & & \\
\hline $\begin{array}{l}\text { Nucleic } \\
\text { acids }\end{array}$ & $\begin{array}{l}\text { miRNA and other } \\
\text { non-coding RNAs, } \\
\text { mRNA, DNA, } \\
\text { histones [29] }\end{array}$ & & $\begin{array}{l}\operatorname{miR} 223, \operatorname{miR} 105, \\
\operatorname{miR} 494[31] \\
\operatorname{miR}-124, \operatorname{miR} 1973 \text { [41] } \\
\text { miR-9, miR-19a [46] }\end{array}$ \\
\hline $\begin{array}{l}\text { Cell-type- } \\
\text { specific } \\
\text { proteins }\end{array}$ & MHC-I [29] & $\begin{array}{l}\text { LFA1, CD14 [29] } \\
\text { Cathepsin D, lysosome- } \\
\text { associated membrane } \\
\text { protein } 1[59]\end{array}$ & $\begin{array}{l}\text { MHC-I, MCH-II, A } \beta P P, \\
\text { PMEL, TCR, FasL, } \\
\text { HSPG, CD } 86, \text { PrP, } \\
\text { TFR, WNT [29] } \\
\text { A } \beta, \text { pTau [38] } \\
\text { MHCII, Lamp-1 and } 2 \\
\text { [47] }\end{array}$ \\
\hline $\begin{array}{l}\text { Other cell- } \\
\text { type specific } \\
\text { molecules }\end{array}$ & & $\begin{array}{l}\text { Transcription factors, } \\
\text { cytokines [38] } \\
\text { TSG101 [82] }\end{array}$ & AMPAR subtypes [41] \\
\hline
\end{tabular}

Abbreviations: A $\beta P$ : A $\beta$ Precursor Protein; ALIX: ALG-2-interacting protein X; AMPAR: hydroxy-5-methy-4isoxazolepropionic acid receptor; CD: Common Determinant; ERK: extracellular signal-regulated kinase; FasL: Fas ligand; FGF: fibroblast growth factor; HSP: heat shock proteins; HSPG: heparan sulfate proteoglycan; Lamp: lysosomal-associated membrane protein; LBPA: lysobisphosphatidic acid; LFA1: lymphocyte function-associated antigen-1; MHC: major histocompatibility complex; miR: microRNA; PLD: phospholipase D; PMEL: premelanosome protein; PrP: prion protein; Rab: Ras superfamily of GTPases; TCR: T-cell receptor; TFR: transferrin recetor; TSG: tumor necrosis factor-stimulated gene-6; TSPAN8: tetraspanin 8; VPS: vacuolar protein sorting; WNT: wingless. 